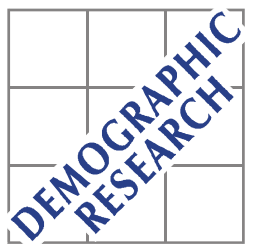

Demographic Research a free, expedited, online journal

of peer-reviewed research and commentary in the population sciences published by the Max Planck Institute for Demographic Research

Konrad-Zuse Str. 1, D-18057 Rostock · GERMANY

www.demographic-research.org

DEMOGRAPHIC RESEARCH

VOLUME 19, ARTICLE 42, PAGES 1551-1574

PUBLISHED 02 SEPTEMBER 2008

http://www.demographic-research.org/Volumes/Vol19/42/

DOI: 10.4054/DemRes.2008.19.42

Research Article

\title{
Adult mortality and children's transition into marriage
}

Kathleen Beegle

Sofya Krutikova

This publication is part of the proposed Special Collection "HIV/AIDS in subSaharan Africa”, edited by Susan Watkins, Jere Behrman, Hans-Peter Kohler, and Simona Bignami-Van Assche.

(C) 2008 Beegle \& Krutikova.

This open-access work is published under the terms of the Creative Commons Attribution NonCommercial License 2.0 Germany, which permits use, reproduction \& distribution in any medium for non-commercial purposes, provided the original author(s) and source are given credit.

See http:// creativecommons.org/licenses/by-nc/2.0/de/ 


\section{Table of Contents}

1 Introduction 1552

$2 \quad$ Empirical strategy and data 1554

3 Results 1560

4 Conclusions 1566

$5 \quad$ Acknowledgements 1567

$\begin{array}{ll}\text { References } & 1568\end{array}$

$\begin{array}{ll}\text { Appendix } & 1571\end{array}$ 


\title{
Adult mortality and children's transition into marriage \\ Kathleen Beegle ${ }^{1}$ \\ Sofya Krutikova ${ }^{2}$
}

\begin{abstract}
Adult mortality due to HIV/AIDS and other diseases is posited to affect children through a number of pathways. On top of health and education outcomes, adult mortality can have significant effects on children by influencing demographic outcomes including the timing of marriage. This paper examines marriage outcomes for a sample of children interviewed in Tanzania in the early 1990s and re-interviewed in 2004. We find that while girls who became paternal orphans married at significantly younger ages, orphanhood had little effect on boys. On the other hand, non-parental deaths in the household affect the timing of marriage for boys.
\end{abstract}

${ }^{1}$ World Bank, U.S.A. Please address correspondence to kbeegle@worldbank.org.

${ }^{2}$ Oxford University, Great Britain. E-mail: sofya.krutikova@economics.ox.ac.uk 


\section{Introduction}

The HIV/AIDS epidemic is expected to have profound impacts on an array of economic and demographic outcomes. Most empirical studies of the impact of high levels of adult mortality caused by HIV/AIDS and other diseases focus on economic outcomes such as poverty and human capital outcomes for orphans. ${ }^{3}$ There are, of course, other important channels through which HIV/AIDS may have long-run effects on the remaining household members, including demographic behaviors. There are fewer studies of the behavioral impact of HIV/AIDS on demographic outcomes such as fertility and marriage among surviving family members. ${ }^{4}$, This study examines the effect of parental death or other adult deaths in households on subsequent transition into marriage. We use longitudinal data from Tanzania, with information on a cohort of children from the baseline who become young adults by 2004 .

There are competing theories of the impact of HIV/AIDS on transitions into marriage. Higher prime-age adult mortality can influence marriage patterns in expectation of mortality outcomes (ex ante) or in response to realized illness or death of household members or parents (ex post). If HIV/AIDS is seen as introducing more risk, then marriage might be an ex ante strategy - a means of geographic diversification and risk sharing amongst household members (see the discussion in McCarthy et al., 2006; Rosenzweig and Stark, 1989). Likewise, lower life expectancy due to the epidemic might encourage people to marry at younger ages. In HIV/AIDS affected communities, marriage might be seen as a way to protect against contracting the disease. ${ }^{5}{ }^{6}$ Bracher et al. (2003), for example, is motivated by the idea that in Malawi and elsewhere in the region marriage is increasingly believed to protect young women from HIV since it may reduce promiscuous sexual behavior, in which case women may be encouraged to marry early. In data from Malawi, Clark et al. (2007) find that about half of women (49\%) and more than half of men (60\%) report that women can avoid HIV through marriage. Rates are similar for reporting that men can avoid HIV through marriage (reported by $42 \%$ of women and $58 \%$ of men). In their study from northern Uganda,

\footnotetext{
${ }^{3}$ See references in Beegle et al. (2006a) for poverty/income studies; see references in Foster and Williamson (2000) and Beegle et al. (2006c) for studies on education and health outcomes for orphans.

${ }^{4}$ The behavioral impact on fertility could be described as an indirect effect rather than direct which constitutes biological effects of HIV and STIs on fecundity. See UN (2002) for a review of studies on the indirect effect often drawing on focus group discussions; also see Taiwo (2006) who examines the impact of orphan fostering on fertility in Malawi and Ainsworth et al. (1998) who examine fertility patterns in households affected by prime-age adult deaths in Tanzania.

${ }^{5}$ Contrary to this perception, it is actually unclear empirically if or how marriage protects young women from contracting AIDS. For example, Clark (2004) shows that adolescent married women in Kenya and Zambia face a higher probability of having contracted HIV than their unmarried counter-parts.

${ }^{6}$ High mortality rates in theory would suggest earlier marriage but for HIV specifically, it may not if the disease is linked with marriage.
} 
Oleke et al. (2006) also report that respondents identified early marriage as a means of preventing infection.

In an ex post framework, as HIV/AIDS affects households through deaths of prime-age household members and increased orphan rates, it may affect marriage patterns. It may, for example, prompt earlier marriage among surviving young adults in instances where these deaths result in income shocks. Among young women, this could occur if they are not earning enough income to support their consumption while at the same time their marriage would contribute resources to the household. ${ }^{7}$ This is a potential impact hypothesized by Foster and Williamson (2000) in their literature review, although they cite no studies which examine this issue. This is also the trend observed by Oleke et al. (2006) in their study of determinants of orphans' wellbeing. However, they find that early marriage among female orphans is explained by the desire of the women themselves, rather than financial or other pressure from their households. They find that female orphans view marriage as an opportunity to improve their quality of life, which tends to be characterized by heavy domestic workload and dropping out of school. In contrast to this line of argument, deaths that lead to labor shortages in the household may result in delayed entry into marriage. Thus, taking a more broad view of family formation and economic crisis, there are theoretical reasons for why economic crisis may delay and hasten marriages, as discussed by Nobles and Buttenheim (2006) in their study of the effect of economic crisis on marriage timing in Indonesia.

While there is little evidence on the impact of adult mortality on children's family formation, there is some indirect evidence that changes in household composition are one of the responses among households to being affected by HIV/AIDS. Hosegood et al. (2004) use demographic surveillance data from rural South Africa and conclude that households experiencing an adult death are vulnerable to dissolution. Yamano and Jayne (2004) find that in rural households in Kenya the death of a male head of household significantly reduces the number of adult women in the household. This trend is proposed to reflect the financial stress incurred by the death, with the outmigration largely attributed to marriage. An earlier version of this work made a more direct connection with the financial gains to households from marriage of daughters; this out-migration was said to "...reflect a coping mechanism to acquire resources through bride dowries." In earlier work using the same data from Tanzania as this study (rounds 1991-1994), Ainsworth et al. (1995) document large changes in household composition over a two-year window observed as a consequence of an adult death in households. The nature of changes in household composition has not been studied more

\footnotetext{
${ }^{7}$ The custom in the region of study in this paper, Kagera, is for a bride price to be negotiated between the man wanting to marry and the woman's parents (or other relatives) (De Weerdt, 2001). Every first marriage is expected to have a bride price associated with it. The bride price includes the makula which is the main gift/transfer. In addition, the makula is accompanied by a long list of other gifts (to other relatives/caregivers).
} 
specifically. For example, these changes could reflect prime-age deaths (and morbidities associated with them) causing more out or in-migration, changes in marriage patterns, differential child fostering behaviors, or other types of restructuring among extended families. $^{8}$

This study focuses on whether marriage patterns among young adults in households affected by adult mortality differ from those in unaffected households in Tanzania. Although we are not directly measuring deaths caused by HIV/AIDS, which is not ascertained in these data, we expect that a large share of parental and prime-age adult deaths that we focus on are attributed to HIV/AIDS (see Ngom and Clark, 2003). We measure whether a young person was affected by HIV/AIDS using two proxy indicators: whether a child became an orphan before age 15 (regardless of whether the parent resided with the child at time of death) and whether the child lived in a household in which a non-parent prime-age adult mortality event occurred after the baseline and before the child turned 15. Although the objective of this work is not to evaluate the outcomes that marriage yields for those who marry, the work is motivated by the perception that the age of marriage can have significant impacts on the future lives of women and their children. Marriage at a younger age increases health risks for women, as well as potentially resulting in "worse" marriage matches. Younger mothers are more likely to suffer from micronutrient deficiencies and be unaware of the health risks associated with pregnancy; they are also more likely to have children soon after marriage which increases the risk of maternal and infant mortality (World Bank, 2007). Younger ages at first marriage may also be associated with curtailed education among girls, although it is difficult to ascertain the causality. Further, a younger bride may be less able to assert power and authority in her marriage especially given that women marry men who are on average several years older. These are points also made by Mensch et al. (2005) in their global study of trends in age at first marriage.

\section{Empirical strategy and data}

Our empirical strategy is to examine the propensity for young adults to be married as a result of a mortality event in their household, conditional on a set of background (premarital) conditions. Our data, discussed below, contain a sample of individuals who are children in 1991-1994 and who are re-interviewed as young adults in 2004 (women 1723 years and men 20-28 years). We use these data to estimate the effect of adult

\footnotetext{
${ }^{8}$ In-migration might actually be the AIDS-affected person. In the 4 rounds of baseline data used in this study, about one-third of prime-age deaths in the baseline survey reflect adult members moving into households less than 6 months before dying.
} 
mortality on probability that an individual is married by 2004 using the following basic specification:

$$
Y_{i j t+s}=\partial_{v}+\alpha_{1} X_{j t}+\alpha_{2} I_{i j t}+\alpha_{3} \text { orphan }_{i j t+s}+\alpha_{4} \text { primedeath }_{i j t+s}+\varepsilon_{i j t+s}
$$

where subscripts index individuals ( $i$ ), households $(j)$, time of first KHDS interview $(t)$, and number of years between baseline interview and last interview (s) (which, in our data, is 10-13 years depending on the round in which the child was interviewed last at baseline). $Y$ is an indicator for having ever been married; for most of the sample, this variable captures the marital status in 2004 as few are divorced or widowed. Since marriage is universal in Tanzania, we interpret the probability of being married in 2004 as reflecting the probability of earlier marriage. We use an indicator for ever married rather than age at first marriage, which would allow for a more refined estimation, because we do not have this information. $X$ and $I$ contain sets of controls for household and individual characteristics, respectively, from baseline. The former includes age, sex and education of the household head, log of expenditure per capita, permanent flooring in the dwelling, and non-farm household. Individual characteristics include age, age squared, an indicator for being in school, and indicators for father and for mother residing in household with the child.

Orphan status (orphan) captures the event of being orphaned prior to age 15. It is separated into being a maternal and paternal orphan. ${ }^{9}$ Finally, our indicator for nonparent adult mortality (primedeath) represents the prime-age (15-49 years) adult death of a household member, excluding parents, which occurred before the child turned 15 . Prime age deaths are split into female and male deaths. Since the economic and social roles of men and women can differ, the gender of the deceased can imply different impacts on children.

We also include district fixed-effects $\left(\partial_{v}\right)$ for the district in which the child resided at baseline; as noted above, by 2004, some children had relocated to new communities which could be as far away as Dar es Salaam. This basic specification is later augmented to include interactions of orphan and primedeath with a set of individual and household characteristics from baseline.

If adult mortality was a random event to which all children were at equal risk, it would be sufficient to know if deaths occurred during childhood and subsequent marital

\footnotetext{
${ }^{9}$ There are few double orphans in the sample and generally there is no additional impact of being a double orphan on the probability of being married in 2004, beyond the additive effect of the maternal and paternal coefficients. Therefore, an indicator for becoming a double orphan by age 15 years was omitted from the final estimations presented here. Likewise, for children who both become orphaned and experience a prime-age death in the household, there could be an additional effect. However, less than 5 percent of children experience both events so we exclude this interactive effect in our estimation.
} 
outcomes in young adulthood. However, specifically because prime-age deaths are premature and are associated with specific behaviors and risk factors, it is possible that there is some "family" effect which influences both the marital outcomes for children and probability of early adult mortality (de Walque, 2006). Specification (1) partially addresses this concern by including a set of baseline characteristics (X) which capture socioeconomic conditions of households in which children reside when young, before deaths occur. Still, there may exist unobserved persistent features of families which are correlated with both early marriage of children and higher mortality probability. As a second attempt to address this endogeneity concern, we will also examine the probability of being married at baseline among young adults as a function of future mortality outcomes to test for these unobservable features.

The data for this study are drawn from a 13-year longitudinal study of people originally residing in the Kagera region of Tanzania in 1991. The Kagera Region of Tanzania is located on the western shore of Lake Victoria, bordering Uganda to the north and Rwanda and Burundi to the west. The population (1.3 million in 1988, about 2 million in 2004) is overwhelmingly rural and primarily engaged in producing bananas and coffee in the northern districts and rain-fed annual crops (maize, sorghum, cotton) in the southern districts. The Kagera Health and Development Survey (KHDS) is a longitudinal socioeconomic survey conducted from September 1991 to January 1994 covering the entire Kagera region (see World Bank, 2004, and http://www.worldbank.org/lsms/) and a follow-up round in 2004 to re-interview all surviving respondents. Because adult mortality of the working age population (15-50) is a relatively rare event and HIV/AIDS was unevenly distributed in Kagera, the KHDS household sample was originally stratified based on the agro-climatic features of the region, levels of adult mortality from the 1988 Census (including both high and low mortality areas), and household-level indicators thought to be predictive of elevated adult illness or mortality. This was done in order to capture a higher percentage of households with a death during the panel 1991-1994 while retaining a control group of households without a death. As a result of the sampling scheme, orphan rates in the KHDS 1991-1994 are more than twice as high as would be observed in a non-stratified random sample although by 2004 rates look close to the population estimates. ${ }^{10}$

\footnotetext{
${ }^{10}$ It is interesting to note that the KHDS 2004 sample is remarkably similar to a random sample of households from Kagera, despite the fact that the baseline sample was not a simple random sample and given the (moderate) attrition since the baseline. The households in the KHDS 2004 had similar characteristics to the CWIQ survey in 2004 (including characteristics such as: household size, female headship, head's education, head's age, land holdings, livestock holdings, and dwelling characteristics) (see CWIQ results in Krutikov and De Weerdt, 2004). Among children under 18 years, 14\% in the KHDS 2004 are single or double-parent orphans and $63 \%$ of children were living with both parents. These numbers are strikingly close to results from the DHS 2003. DHS 2003 survey found that $11 \%$ of the children under 18 years old in Kagera had lost one or both parents (the number equal to rate in the Tanzanian national sample). In the DHS, $60 \%$ of children in Kagera who were under 18 years of age live with both parents.
} 
Households are defined as groups of individuals who normally take their meals together and sleep in the same dwelling, with the exception of household heads who can be absent. The membership of households and headship was defined by the respondents themselves.

The goal of the KHDS 2004 was to re-interview the sample of about 6,200 respondents from the 1991-1994 survey (which excludes 169 individuals who died over the course of the baseline rounds) (Beegle et al., 2006b). Considerable effort was made to track surviving respondents to their current location, be it in the same community (typically a village), a nearby community, within the region, or even outside the region. This is an important feature since the event being studied, marriage, is often (almost always) associated with the young person moving out of the dwelling they occupied prior to marriage. ${ }^{11}$ Among the surviving children in the two gender-based age groups used here, 77 percent were located and re-interviewed, 5 percent had died and 18 percent were not located in 2004. Of those reinterviewed, 46 percent were residing outside of the baseline community. Without making an effort to track individuals who left the village, therefore, the re-contact rate would have fallen to 54 percent of the surviving children. Despite the low rate of attrition, however, it remains a concern. While attrition linked to unobservables cannot be addressed using this data set, as proposed in Fitzgerald et al. (1998), the possibility of attrition linked to observables is explored by estimating a weighted version of the main specification; the weights are the inverse of the predicted probability of a child from the baseline remaining in the sample.

For this study, the subsample of interest is the group of young people who are of pre-marital age at baseline and are age-eligible for marriage by 2004. Fifteen years is the upper-bound not only for being considered of pre-marital age, but also the cut-off for defining someone as an orphan or experiencing a death of a household member. The cut-off of 15 years to define orphanhood is consistent with much of the literature in this area, although some more recent work extends the age cut-off to 18 years (see UNAIDS, 2004). The lower age bound for being in the sample are those children in the baseline who would be of marrying age by 2004. The main sample therefore consists of children ages 4-15 at baseline; by 2004, these children were between the ages of 17 and 28 -- meaning that they had all moved into "marrying" ages between the baseline and

\footnotetext{
${ }^{11}$ The success of panel surveys is often measured in terms of re-contact of households, rather than individuals therein. By this measure, excluding households in which all previous members are deceased (17 households with 31 people), the KHDS 2004 survey re-contacted 93\% of the baseline households (835 out of 895 households). This is an excellent rate of re-contact compared to panel surveys in low-income countries and high-income countries. The KHDS panel has an attrition rate that is much lower than that of other well-known panel survey summarized in Alderman et al. (2001). Notably, most of the surveys in Alderman et al. cover considerably shorter time periods (2 - 5 years). Refusals in the KHDS were relatively uncommon; the main reason for not re-interviewing surviving panel respondents was failure to locate the respondent.
} 
follow-up. We use different age ranges for men and women to reflect marriage patterns in Tanzania. We censor the ages for the sample of women to age 23 because after age 23 only a very small proportion of women have never married. ${ }^{12}$ Among men, on the other hand, roughly 2 percent were married at the age of 18 (NBS, 2005); this is also consistent with the findings in the KHDS data. Therefore, the sample of men in this study consists of those between the ages of 20 and 28 in 2004. Marriage in this setting is a partnership recognized by families and communities, regardless of explicit legal or religious sanction at the onset. In fact, according to the Law of Marriage Act of Tanzania, after two years of cohabitation as a couple, a man and a woman are considered to be legally married (Rwezaura, 1998).

We have two proxy measures for being affected by HIV/AIDS after the baseline round: being orphaned and having experienced a prime-age death (ages 15-49) of an individual in the household who is not the parent. The latter group is not necessarily determined randomly since individuals choose in which households to reside (similar to the choice to foster a child in or out). Still, these adults are close relatives of the sample of children. We would ideally have some information on the determinants of coresiding non-parental adults, such as whether it is low (high) income adults with whom these children co-reside; this might enable us to nuance the interpretation of our estimates. With exception of the limited subset of adults who moved between baseline rounds, for the majority of adults, we cannot identify the pattern of household formation. They may have moved into the household with the child, or the child (and his/her parent(s)) could have moved in with this adult. Our set of household characteristics is, in turn, determined by this membership pattern.

We will focus on the sub-sample of children who were not orphaned at baseline. Children orphaned at baseline are excluded since we do not have data on preorphanhood characteristics of these children. These are characteristics which may be correlated with current orphanhood status the omission of which is likely to lead to endogeneity and omitted variable bias; this is the standard problem encountered by studies which only use cross-sectional data to evaluate the impact of orphanhood. We then assess the impact of orphanhood and deaths of prime-age household members between 1991-94 and 2004 on the probability of being married by 2004, controlling for child and household characteristics at baseline.

Among the sample of non-orphans at baseline, 22 percent became orphaned before the age of 15 (Table 1). Most of these are single-parent orphans; only 3 percent of the sample experienced the death of both parents before they were 15 years old. Fewer children experienced the second type of mortality shock - a non-parent, adult mortality

\footnotetext{
${ }^{12}$ Nationally, the median age at marriage in rural Tanzania is 18 for women and 24 for men (NBS, 2005). More than $87 \%$ of women ages $25-29$ were married by age 25 . Among men, this statistic is $63 \%$. Less than $5 \%$ of women $15-19$ years were married by age 15 .
} 
event - than a parental death; 13 percent experienced the death of a prime-age adult before the age of 15, of which 7 percent suffered the death of an adult male and 7 percent suffered that of an adult female. Overall, 30 percent of the sample of children experienced at least one of these four mortality shocks; 9 percent suffered more than one of these four mortality shocks.

\section{Table 1: $\quad$ Summary statistics}

\begin{tabular}{|c|c|c|c|c|c|c|}
\hline & \multicolumn{2}{|c|}{ All } & \multicolumn{2}{|c|}{$\begin{array}{c}\text { Women } \\
(17-23 \text { in } 2004)\end{array}$} & \multicolumn{2}{|c|}{$\begin{array}{c}\text { Men } \\
(20-28 \text { in 2004) }\end{array}$} \\
\hline & Mean & s.d. & Mean & s.d. & Mean & s.d. \\
\hline \multicolumn{7}{|l|}{ Outcome (2004) } \\
\hline Married ${ }^{r}$ & 0.48 & $(0.50)$ & 0.53 & $(0.50)$ & 0.43 & $(0.50)$ \\
\hline \multicolumn{7}{|l|}{ Adult mortality in household after baseline and before age 15} \\
\hline Male prime-age adult died (excluding father) ${ }^{r}$ & 0.07 & $(0.26)$ & 0.09 & $(0.28)$ & 0.06 & $(0.23)$ \\
\hline Female prime-age adult died (excluding mother) ${ }^{r}$ & 0.07 & $(0.26)$ & 0.09 & $(0.29)$ & 0.06 & $(0.23)$ \\
\hline \multicolumn{7}{|l|}{ Orphanhood events after baseline and before age 15} \\
\hline Father died ${ }^{\Upsilon}$ & 0.17 & $(0.38)$ & 0.25 & $(0.44)$ & 0.10 & $(0.30)$ \\
\hline Mother died ${ }^{\Upsilon}$ & 0.08 & $(0.28)$ & 0.11 & $(0.32)$ & 0.06 & $(0.24)$ \\
\hline \multicolumn{7}{|l|}{ Baseline variables (1991-1994) } \\
\hline Household head has at least primary education $r$ & 0.28 & $(0.45)$ & 0.28 & $(0.45)$ & 0.28 & $(0.45)$ \\
\hline Household head is male ${ }^{\gamma}$ & 0.87 & $(0.34)$ & 0.85 & $(0.36)$ & 0.89 & $(0.31)$ \\
\hline Age of household head & 51.1 & $(14.0)$ & 49.7 & $(13.7)$ & 52.3 & $(14.1)$ \\
\hline Log of expenditure per capita & 11.3 & (2.3) & 11.5 & $(1.9)$ & 11.2 & $(2.6)$ \\
\hline Permanent flooring in dwelling ${ }^{\Upsilon}$ & 0.15 & $(0.36)$ & 0.14 & $(0.35)$ & 0.15 & $(0.36)$ \\
\hline Non-farm household ${ }^{r}$ & 0.25 & $(0.43)$ & 0.25 & $(0.43)$ & 0.25 & $(0.44)$ \\
\hline Father lives in household $r$ & 0.73 & $(0.44)$ & 0.72 & $(0.45)$ & 0.75 & $(0.44)$ \\
\hline Mother lives in household ${ }^{\Upsilon}$ & 0.77 & $(0.42)$ & 0.78 & $(0.42)$ & 0.77 & $(0.42)$ \\
\hline Number of observations & \multicolumn{2}{|c|}{683} & \multicolumn{2}{|c|}{320} & \multicolumn{2}{|c|}{363} \\
\hline
\end{tabular}

Notes: Sample excludes respondents who were one or two parent orphans at baseline. All observations were no older than 15 at baseline and unmarried. All covariates in table are binary indicators ( 1 if true, else 0 ). Log of expenditure per capita is the annual level of household consumption expenditure in 2004 Tanzania shilling prices. ${ }^{\Upsilon}$ indicates binary (0/1) variables.

Table 1 presents the set of control variables which includes, among others, indicators for wealth/poverty status (head's education, per capita expenditure, flooring material). Even when parents are alive, children do not necessarily reside with them. As is the case in other Sub-Saharan countries, the rate of fostering of children is high in Tanzania; while fostering is associated with orphanhood, many non-orphaned children are not residing with one or both surviving parents. A quarter of the children in the sample were not residing with their father or not residing with their mother at baseline. About 16 percent of children did not reside with either parent at baseline. Of these, 61 percent and 9 percent were grandchildren and nieces/nephews of the household head. The others were related to the household head with exception of two children who were 
non-relatives. Fostering prior to parental death could potentially reflect a strategic decision on the part of families. However, taking into consideration that an average length of illness before adult deaths is reported at about one year and the large span of the panel survey, we suspect that baseline fostering does not reflect ex ante adjustments in living arrangements in expectation of a death. Nevertheless, fostering status of the children (all of whom are non-orphans at baseline by sample definition) is included as one of the controls for baseline individual characteristics. More than two-thirds of children (71\%) co-resided with a non-parent adult age 16 or over at baseline. Most (60\%) of these non-parental adults are siblings, and the remainder are mostly aunts/uncles or cousins of the child.

\section{Results}

The main findings are presented in Table 2. The first column shows the results for the whole sample; the sample is then split by gender in the second and third columns. The results presented are the marginal effects estimated from Probit models. They can be interpreted as the percentage point change in the probability of being married in 2004 for a one unit change in the independent variable. Overall, while neither the death of a prime-age male household member nor parental death appear to have any affect on the probability of early marriage for the whole sample, female death reduces this probability by 14 percentage points. However, results presented in columns 2 \& 3 reveal a very different pattern when the sample is split by gender. The loss of a father before the age of 15 , results in a 13 percentage point increase in the probability of being married among women age 17-23. This effect is both extremely large and statistically significant. At the mean, this translates into a 25 percent increase in marriage probability. In contrast, neither paternal nor maternal orphanhood have any impact on transition into marriage among men. For men, marriage probability responds to the death of non-parental adult females in the household; men have a higher probability of postponing marriage in this instance. The probability of marriage declines by a large and significant amount of 31 percentage points.

Among other covariates, there is some indication that marriage among young women from wealthier households is delayed compared to their less-wealthy counterparts, where wealth is measure by presence of permanent flooring in the dwelling. While there is no significant relationship between wealth and probability of marriage among men, those from male-headed households are less likely to be married by 2004 (significant at 10.6\%). 
Table 2: $\quad$ The effect of orphanhood on probability of marriage by 2004 (Dependent variable: ever married)

\begin{tabular}{|c|c|c|c|}
\hline & $\begin{array}{l}\text { (1) } \\
\text { All }\end{array}$ & $\begin{array}{c}(2) \\
\text { Women } \\
(17-23 \text { in } 2004)\end{array}$ & $\begin{array}{c}\text { (3) } \\
\text { Men } \\
(20-28 \text { in 2004) }\end{array}$ \\
\hline Male prime-age adult died & $\begin{array}{l}-0.042 \\
(0.088)\end{array}$ & $\begin{array}{l}-0.113 \\
(0.128)\end{array}$ & $\begin{array}{c}0.058 \\
(0.121)\end{array}$ \\
\hline Female prime-age adult died & $\begin{array}{l}-0.139^{\star} \\
(0.080)\end{array}$ & $\begin{array}{l}-0.064 \\
(0.121)\end{array}$ & $\begin{array}{c}-0.308^{\star \star \star} \\
(0.088)\end{array}$ \\
\hline Father died & $\begin{array}{r}0.071 \\
(0.061)\end{array}$ & $\begin{array}{c}0.126^{*} \\
(0.076)\end{array}$ & $\begin{array}{l}-0.005 \\
(0.110)\end{array}$ \\
\hline Mother died & $\begin{array}{r}0.016 \\
(0.076)\end{array}$ & $\begin{array}{r}0.020 \\
(0.101)\end{array}$ & $\begin{array}{l}-0.021 \\
(0.129)\end{array}$ \\
\hline Male & $\begin{array}{c}-0.501^{\star \star \star} \\
(0.049)\end{array}$ & & \\
\hline \multicolumn{4}{|l|}{ Baseline characteristics } \\
\hline Head has at least primary schooling & $\begin{array}{l}-0.029 \\
(0.054)\end{array}$ & $\begin{array}{l}-0.131 \\
(0.081)\end{array}$ & $\begin{array}{r}0.036 \\
(0.075)\end{array}$ \\
\hline Head male & $\begin{array}{l}-0.093 \\
(0.074)\end{array}$ & $\begin{array}{c}0.002 \\
(0.114)\end{array}$ & $\begin{array}{l}-0.170 \\
(0.105)\end{array}$ \\
\hline Age of household head & $\begin{array}{l}-0.003 \\
(0.002)\end{array}$ & $\begin{array}{l}-0.005^{\star} \\
(0.003)\end{array}$ & $\begin{array}{l}-0.002 \\
(0.002)\end{array}$ \\
\hline Log of expenditure per capita & $\begin{array}{r}0.014 \\
(0.047)\end{array}$ & $\begin{array}{r}0.005 \\
(0.070)\end{array}$ & $\begin{array}{c}0.002 \\
(0.066)\end{array}$ \\
\hline Permanent flooring in dwelling & $\begin{array}{c}-0.160^{\star \star \star} \\
(0.061)\end{array}$ & $\begin{array}{l}-0.196^{\star \star} \\
(0.095)\end{array}$ & $\begin{array}{l}-0.106 \\
(0.082)\end{array}$ \\
\hline Non-farm household & $\begin{array}{l}-0.031 \\
(0.057)\end{array}$ & $\begin{array}{l}-0.008 \\
(0.088)\end{array}$ & $\begin{array}{l}-0.037 \\
(0.074)\end{array}$ \\
\hline Father lives in household & $\begin{array}{r}0.049 \\
(0.066)\end{array}$ & $\begin{array}{r}0.003 \\
(0.102)\end{array}$ & $\begin{array}{r}0.078 \\
(0.087)\end{array}$ \\
\hline Mother lives in household & $\begin{array}{l}-0.003 \\
(0.062)\end{array}$ & $\begin{array}{l}-0.001 \\
(0.089)\end{array}$ & $\begin{array}{l}-0.032 \\
(0.091)\end{array}$ \\
\hline Observations & 683 & 320 & 363 \\
\hline Pseudo R-squared & 0.198 & 0.233 & 0.209 \\
\hline
\end{tabular}

Notes: Results reported are marginal effects estimated using a Probit. Robust standard errors in brackets. * significant at $10 \%$; * significant at 5\%; ${ }^{\star \star \star}$ significant at $1 \%$. Includes controls for age and age squared, district fixed effects and whether child was in school at baseline. 
Table 3: The effect of orphanhood on probability of marriage by 2004 with interactions, women (Dependent variable: ever married)

\begin{tabular}{|c|c|c|c|}
\hline & (1) & (2) & (3) \\
\hline \multirow[t]{2}{*}{ Male prime-age adult died } & -0.121 & -0.094 & -0.113 \\
\hline & $(0.128)$ & $(0.142)$ & $(0.144)$ \\
\hline \multirow[t]{2}{*}{ Female prime-age adult died } & -0.061 & -0.054 & 0.028 \\
\hline & $(0.121)$ & $(0.153)$ & $(0.159)$ \\
\hline \multirow[t]{2}{*}{ Father died } & $0.174^{*}$ & $0.139^{*}$ & $0.178^{*}$ \\
\hline & $(0.098)$ & $(0.083)$ & $(0.097)$ \\
\hline \multirow[t]{2}{*}{ Mother died } & -0.020 & 0.031 & -0.141 \\
\hline & $(0.182)$ & $(0.120)$ & $(0.166)$ \\
\hline \multicolumn{4}{|l|}{ Interactions } \\
\hline \multirow[t]{2}{*}{ Father died \& in school } & -0.086 & & \\
\hline & $(0.128)$ & & \\
\hline \multirow[t]{2}{*}{ Mother died \& in school } & 0.050 & & \\
\hline & $(0.207)$ & & \\
\hline \multirow[t]{2}{*}{ Father died \& non-farm household } & & -0.102 & \\
\hline & & $(0.187)$ & \\
\hline \multirow[t]{2}{*}{ Mother died \& non-farm household } & & -0.047 & \\
\hline & & $(0.220)$ & \\
\hline \multirow[t]{2}{*}{ Male adult died \& non-farm household } & & -0.179 & \\
\hline & & $(0.340)$ & \\
\hline \multirow[t]{2}{*}{ Female adult died \& non-farm household } & & 0.055 & \\
\hline & & $(0.242)$ & \\
\hline \multirow[t]{2}{*}{ Father died \& rich household } & & & -0.090 \\
\hline & & & $(0.137)$ \\
\hline \multirow[t]{2}{*}{ Mother died \& rich household } & & & 0.268 \\
\hline & & & $(0.166)$ \\
\hline \multirow[t]{2}{*}{ Male adult died \& rich household } & & & -0.039 \\
\hline & & & $(0.257)$ \\
\hline \multirow[t]{2}{*}{ Female adult died \& rich household } & & & -0.170 \\
\hline & & & $(0.131)$ \\
\hline \multicolumn{4}{|l|}{ Chi-squared tests: probability value } \\
\hline Father died plus interaction $=0$ & 0.34 & 0.82 & 0.40 \\
\hline Mother died plus interaction $=0$ & 0.80 & 0.93 & 0.27 \\
\hline Observations & 320 & 320 & 320 \\
\hline R-squared & 0.234 & 0.234 & 0.239 \\
\hline
\end{tabular}

Notes: Results reported are marginal effects estimated using a Probit. Robust standard errors in brackets. * significant at $10 \%$; * significant at $5 \%$; ${ }^{\star \star \star}$ significant at $1 \%$. Includes controls for age and age squared, district fixed effects, whether child was in school at baseline and baseline characteristics in Table 2 (head's education, sex, and age; log PCE; flooring material; non-farm status of household; father/mother living in household.). Column 1 includes indicator for being in school at baseline.

Tables 3 and 4 explore the effects of orphanhood and the death of a prime age household member by specific individual and household characteristics for the samples of women and men, respectively. The additional variables include an indicator for 
whether the child was in school at baseline, and interactions of orphanhood with two household characteristics from baseline: the head was employed in non-farming and the household had per capita consumption above the median. ${ }^{13}$ Because of the low frequency of our variables of interest (mortality shock), we are careful in our interpretation of the interactions where means are, of course, smaller.

Table 4: The effect of orphanhood on probability of marriage by 2004 with interactions, men (Dependent variable: ever married)

\begin{tabular}{|c|c|c|c|}
\hline & (1) & (2) & (3) \\
\hline \multirow[t]{2}{*}{ Male prime-age adult died } & 0.059 & 0.074 & 0.063 \\
\hline & $(0.122)$ & $(0.138)$ & $(0.150)$ \\
\hline \multirow[t]{2}{*}{ Female prime-age adult died } & $-0.307^{\star \star \star}$ & $-0.369 * \star \star$ & $-0.344^{\star \star \star}$ \\
\hline & $(0.088)$ & $(0.078)$ & $(0.099)$ \\
\hline \multirow[t]{2}{*}{ Father died } & -0.052 & 0.111 & 0.040 \\
\hline & $(0.170)$ & $(0.136)$ & $(0.146)$ \\
\hline \multirow[t]{2}{*}{ Mother died } & -0.097 & 0.103 & -0.105 \\
\hline & $(0.293)$ & $(0.191)$ & $(0.166)$ \\
\hline \multicolumn{4}{|l|}{ Interactions } \\
\hline \multirow[t]{2}{*}{ Father died \& in school } & 0.075 & & \\
\hline & $(0.220)$ & & \\
\hline \multirow[t]{2}{*}{ Mother died \& in school } & 0.101 & & \\
\hline & $(0.352)$ & & \\
\hline \multirow[t]{2}{*}{ Father died \& non-farm household } & & $-0.389 * \star \star$ & \\
\hline & & $(0.067)$ & \\
\hline \multirow[t]{2}{*}{ Mother died \& non-farm household } & & -0.275 & \\
\hline & & $(0.170)$ & \\
\hline \multirow[t]{2}{*}{ Male adult died \& non-farm household } & & -0.126 & \\
\hline & & $(0.253)$ & \\
\hline \multirow[t]{2}{*}{ Female adult died \& non-farm household } & & 0.348 & \\
\hline & & $(0.280)$ & \\
\hline \multirow[t]{2}{*}{ Father died \& rich household } & & & -0.122 \\
\hline & & & (0.195) \\
\hline \multirow{2}{*}{ Mother died \& rich household } & & & 0.165 \\
\hline & & & $(0.264)$ \\
\hline \multirow[t]{2}{*}{ Male adult died \& rich household } & & & -0.030 \\
\hline & & & $(0.231)$ \\
\hline \multirow[t]{2}{*}{ Female adult died \& rich household } & & & 0.213 \\
\hline & & & $(0.294)$ \\
\hline \multicolumn{4}{|l|}{ Chi-squared tests: probability value } \\
\hline Father died plus interaction $=0$ & 0.88 & 0.03 & 0.58 \\
\hline Mother died plus interaction $=0$ & 0.97 & 0.27 & 0.80 \\
\hline Observations & 363 & 363 & 363 \\
\hline R-squared & 0.209 & 0.221 & 0.208 \\
\hline
\end{tabular}

Notes: Results reported are marginal effects estimated using a Probit. Robust standard errors in brackets. * significant at $10 \%$; ** significant at 5\%; ${ }^{\star \star \star}$ significant at $1 \%$. Includes controls for age and age squared, district fixed effects, whether child was in school at baseline and baseline characteristics in Table 2 (head's education, sex, and age; log PCE; flooring material; non-farm status of household; father/mother living in household.). Column 1 includes indicator for being in school at baseline.

${ }^{13}$ The indicator for being in school at baseline is motivated specifically by findings in Beegle et al. (2006c) which found that orphanhood was associated with lower schooling among those children not in school when orphaned. 
The results indicate that the significant positive effect of paternal orphanhood on the probability of marriage among young women only holds for those who were not at school at the time of paternal death (Table 3 column 1 ). ${ }^{14}$ In column 2, results show that the impact of paternal mortality on probability of marriage also varies depending on the occupational sector of the head of the household. We find that orphanhood has a significant impact on transition into marriage among women who, at a young age, were living in households headed by individuals employed in farming as opposed to nonfarming sectors (mainly non-farm enterprise activities rather than wage employment). Finally, the impact of paternal orphanhood on propensity to marry among girls is concentrated among poorer girls (column 3). Girls in rich households are protected from earlier marriage if their father dies relative to poor girls.

For men, we find no impact of paternal or maternal orphanhood on probability of marriage regardless of schooling status when orphaned (Table 4 column 1). In contrast, while paternal death has no significant impact on the probability of marriage among men who were raised in farming households, it does significantly reduce the probability of marriage among those raised in households headed by individuals in the non-farming sector (Table 4 column 2). The loss of a father before the age of 15 among boys from these households results in a 28 percentage point decrease in the probability of being married. Non-farm households are largely engaged in non-farm enterprise activities, so that the death of the father may increase demand for the boy to work in this enterprise. This work experience, in turn, might actually make a young man more "marriageable", although the net effect is to delay marriage. In contrast, because the region is densely populated, farms are not associated with labor shortages in general. The significant negative impact of death of a prime age female household member, on the other hand, is concentrated among boys raised in farm households and in poorer households (columns 2 and 3). This is consistent with the labor of boys substituting for the work of women (excluding mothers) in the household and resulting in delayed marriage. We do not, however, see this effect when boys become maternal orphans. Possibly this is because the mothers were not all residing with the son since fostering is not uncommon.

The preceding results are based on a sample that is limited to those who were nonorphaned at baseline, with mortality shocks being restricted to those taking place between survey rounds. This reduces the sample size, particularly among older children in the age range 4-15, since orphanhood rates sharply increase with age. The motivation was to control for pre-orphan characteristics of the children and the household information available in the baseline survey (13 years earlier). It is predicated on the

\footnotetext{
${ }^{14}$ Although the mitigating effect of being in school and being a paternal orphan is not significant, as noted above, we are careful in our interpretation since events are infrequent. We compare all our interaction results by re-estimating the specifications in Tables 3 and 4 using the opposite set of interactions: not being in school, being a farm household, and having per capita expenditure below the median.
} 
idea that orphanhood may be a non-random event, in which case traditional crosssectional analysis will be problematic. We explore the importance of the baseline controls and sample restriction in two ways. First, we can examine results omitting baseline characteristics (Annex Table 1). Second, we can estimate the equation on the entire sample which includes orphans at baseline (Annex Table 2).

The results show that both the significance and the magnitude of the positive effect of paternal orphanhood on the probability of marriage among women are reduced when initial household characteristics are not controlled for (Annex Table 1, column 2). The results using this specification show that paternal orphanhood increases the probability of marriage among women by 11 percentage points. However, this effect is only significant at a 13 percent level of confidence. In contrast, neither the magnitude nor the significance of the negative effect of the death of a prime-age female household member on probability of marriage among men changes with the exclusion of controls for initial household characteristics.

Expanding the sample to include those who were already orphaned at the time of the baseline further reduces the significance of the impact of paternal death on probability of marriage among women (Annex Table 2, column 2). It also results in the loss of magnitude and significance in the impact of the death of prime-age female household members on probability of marriage among men (column 3). Both results in Annex 1 and 2 suggest that not controlling for household and individual characteristics prior to the mortality shock may introduce bias in estimating the effect of a mortality shock on probability of earlier marriage.

We can further explore whether young adults at baseline were more likely to be married if, in the future, they become orphans or a household member dies, as discussed above. Ideally, we would like to explore this relationship for the older siblings of those in the sample in preceding analysis. However, we only have data on co-resident older siblings and most married siblings will have moved out. Instead, we examine the marital status of the set of non-orphaned young adults (women 17-23 and men 20-28) at baseline. There are 507 such people. For all of them, we have measures of adult mortality and, for 429 of them, we know their future orphan status (they were reinterviewed in 2004). The motivation for this analysis is to explore the possibility that some omitted variables which are correlated with orphan status and earlier marriage drive the results. That is, we want to explore if the findings above are picking up this correlation rather than the impact of being orphaned on marriage.

The results suggest that there is no association between probability of marriage and future adult mortality. Neither parental death nor the death of a prime-age household member in the future has a significant impact on the probability of being married in the present among young adults in the baseline. 
Finally, the possibility of non-random attrition is explored by looking at attrition linked to observable characteristics. Results from a logit regression of attrition status on a set of household and individual level baseline characteristics (including district indicator variables to control for district level unobservables), shows that there are some significant associations. In particular, while co-habitation with the father in the baseline significantly reduces the probability of not being re-interviewed in 2004, attrition is higher for girls and individuals from better-off households. This suggests that nonrandom attrition may pose a problem for establishing a causal relationship between transition into marriage and adult death in the household.

One way of addressing this, as proposed by Fitzgerald et al. (1998), is to use the inverse of the predicted probability that an individual remained in the sample by 2004 as weights in the main specification. The probabilities are predicted from the above logistic regression and the results are presented in Annex Table 3. Weighting the observations does not noticeably alter the magnitude of the effects estimated in Table 2 . The significance of some of these effects declines slightly. Nevertheless, none of the significant results in the weighted regressions have a level of confidence lower than 85 percent, suggesting that attrition is not contaminating the main findings.

\section{Conclusions}

There are numerous channels through which increased adult mortality due to HIV/AIDS and other diseases could affect demographic behaviors. This paper investigates one such behavior: the probability of earlier marriage among young adults. By extending the existing research beyond schooling and health outcomes for children, this study provides new evidence on the demographic impact of increased adult mortality. Using panel data from Tanzania, the study examines the marriage outcomes of young adults who were followed from childhood for 13 years. The results show a large positive and statistically significant impact of a father's death on the likelihood of marriage for women. This effect suggests that paternal orphanhood reduces the probability of marriage among women between the ages of 17 and 23 years by 32 percent. For instance, while on average 58 percent of women are married by the age of 20, with the orphan effect this proportion increases to 75 percent. However, this impact varies substantially across girls from different backgrounds. Female paternal orphans most affected include girls from poorer households, from households whose primary source of income is farming, and girls who were not in school when orphaned. For young men, on the other hand, neither mother nor fathers' deaths are associated with differential transition into marriage with exception of parental orphans in households engaged in non-farm activities. 
In contrast, while the death of a prime age adult has no impact on transition into marriage among women, the death of a prime-age female household member strikingly reduces the probability of marriage among men. For instance, while on average 54 percent of men are married by the age of 25 , the effect of the death of a prime-age female household member reduces this proportion to only 35 percent.

Earlier marriage for young women who are orphaned is a cause for serious concern. Depending on trends in orphanhood rates in HIV/AIDS affected countries, this effect can undermine long-term trends towards delaying marriage observed in many sub-Saharan African countries (see Mensch et al., 2005). A shift to early marriage may be associated with a wide range of worse human development outcomes for women and for their children. Effectively addressing this issue, however, requires further investigation to understand the underlying mechanisms through which orphanhood affects entry into marriage.

\section{Acknowledgements}

The views expressed here do not necessarily reflect those of the World Bank or its member countries. We thank Shelley Clark, Stefan Dercon, an anonymous referee, Jere Behrman and seminar participants 2006 Malawi Diffusion and Ideational Change Project Conference "Panel research on HIV/AIDS and other sexually transmitted infections in sub-Saharan Africa” for very useful comments. 


\section{References}

Ainsworth, M., Filmer, D., and Semali, I. (1998). The Impact of AIDS Mortality on Individual Fertility: Evidence from Tanzania. In: Montgomery, M. and Cohen, B. (eds.). From Death to Birth: Mortality Decline and Reproductive Change. Washington, DC: National Academy Press.

Ainsworth, M, Ghosh, S., and Semali, I. (1995). The Impact of Adult Deaths on Household Composition in Kagera Region, Tanzania. [unpublished manuscript]. Policy Research Department, World Bank, Washington, D.C.

Alderman, H., Berhman, J.R., Kohler, H., Maluccio, J., and Watkins S. (2001). Attrition in Longitudinal Household Survey Data: Some Tests for Three DevelopingCountry Samples. Demographic Research 5(4): 78-124.

Beegle, K., De Weerdt, J., and Dercon, S. (2006a). Adult Mortality and Economic Growth in the Age of HIV/AIDS. Economic Development and Cultural Change forthcoming.

Beegle, K., De Weerdt, J., and Dercon, S. (2006b). Kagera Health and Development Survey (KHDS), 2004, Basic Information Document. mimeo, the World Bank.

Beegle, K., De Weerdt, J., and Dercon, S. (2006c). Orphanhood and the Long-Run Impact on Children. American Journal of Agricultural Economics 88: 12661272

Bracher, M., Santow, G., and Watkins, S. (2003). Moving and Marrying. Demographic Research Special Collection 1: Article 7.

Clark, S. (2004). Early Marriage and HIV Risks in Sub-Saharan Africa. Studies in Family Planning 35(3): 149-160.

Clark, S., Poulin, M., and Kohler, H.-P. (2007). The Marital Process and HIV/AIDS in Rural Malawi. Population Studies Center Working Paper Series PSC 07-02.

De Walque, D. (2006). Who Gets AIDS and How? The Determinants of HIV Infection and Sexual Behaviors in Burkina Faso, Cameroon, Ghana, Kenya and Tanzania. World Bank Policy Research Working Paper No. 3844.

De Weerdt, J. (2001). Community Organisations in Rural Tanzania: A Case Study of the Community of Nyakatoke, Bukoba Rural District. manuscript, EDI Tanzania.

Fitzgerald, J., Gottschalk, P., and Moffitt, R. (1998). An Analysis of Sample Attrition in Panel Data. Journal of Human Resources 33 (2): 251-299. 
Foster, G. and Williamson, J. (2000). A Review of Current Literature of the Impact of HIV/AIDS on Children in Sub-Saharan Africa. AIDS 14(Suppl. 3): S275-S284.

Hosegood, V., McGrath, N., Herbst, K., and Timaeus, I.M. (2004). The Impact of Adult Mortality on Household Dissolution and Migration in Rural South Africa. AIDS 18:1585-1590.

Krutikov, S. and De Weerdt, J. (2004). Kagera Rural CWIQ: Baseline Survey on Poverty, Welfare and Services in Kagera Rural Districts [unpublished manuscript]. EDI - Tanzania.

McCarthy, N., Carletto, G., Davis, B., and Maltsoglu, I. (2006). Unlocking the Potential of Agriculture in Albania: The Role of Migration [unpublished manuscript].

Mensch, B. S., Singh, S., and Casterline, J.B. (2005). Trends in the Timing of First Marriage Among Men and Women in the Developing World. In: Lloyd, C.B., Behrman, J.R., Stromquist, N.P., and Cohen, B. (eds.) The Changing Transitions to Adulthood in Developing Countries: Selected Studies, Panel on Transitions to Adulthood in Developing Countries, Committee on Population, Division of Behavioral and Social Sciences and Education, Washington, DC: National Academies Press.

National Bureau of Statistics (NBS) Tanzania and ORC Macro (2005). Tanzania Demographic and Health Survey 2004-05. Dar es Salaam, Tanzania: National Bureau of Statistics and ORC Macro.

Ngom, P. and Clark, S. (2003). Adult Mortality in the Era of HIV/AIDS: Sub Saharan Africa. Workshop on HIV/AIDS and Adult Mortality in Developing Countries, Population Division, Department of Economic and Social Affairs, United Nations Secretariat, New York.

Nobles, J. and Buttenheim, A. (2006). Marriage in Periods of Crisis: Evidence from Indonesia. California Center for Population Research Working Paper 017-06.

Oleke, C., Blystad, A., Moland, K.M., Rekdal, O.B., and Heggenhougen, K. (2006). The Varying Vulnerability of African Orphans: The Case of the Langi, Northern Uganda. Childhood 13(2): 267-284.

Rosenzweig, M.R. and Stark, O. (1989). Consumption Smoothing, Migration, and Marriage: Evidence from Rural India. Journal of Political Economy 97(4): 905926.

Rwezaura, B. (1998). The Proposed Abolition of De Facto Unions in Tanzania: A Case of Sailing Against the Social Current. Journal of African Law 42: 187-214. 
Taiwo, O. (2006). Sharing The Burden of Death: Network Effects of Mortality Shocks on Fertility and Child Health in Family Implicit Insurance. mimeo, Brown University.

United Nations (2002). HIV/AIDS and Fertility in Sub-Saharan Africa: A Review of the Research Literature. UN: NY.

UNAIDS, UNICEF and USAID (2004). Children on the Brink 2004: A Joint Report of New Orphan Estimates and a Framework for Action. UN.

World Bank (2004). User's Guide to the Kagera Health and Development Survey Datasets. mimeo.

World Bank (2007). World Development Report 2007: Development and the Next Generation. World Bank.

Yamano, T. and Jayne, T.S. (2004). Measuring the Impacts of Working-Age Adult Mortality on Small-Scale Farm Households in Kenya. World Development 32(1): 91-119. 


\section{Appendix}

\section{Annex Table 1: The effect of orphanhood, with no baseline controls (Dependent variable: ever married)}

\begin{tabular}{lccc}
\hline & $(1)$ & $\begin{array}{c}(2) \\
\text { Women } \\
(17-23 \text { in 2004) }\end{array}$ & $\begin{array}{c}(3) \\
\text { Men } \\
(20-28 \text { in 2004) }\end{array}$ \\
\hline Male prime-age adult died & All & -0.152 & 0.077 \\
Female prime-age adult died & -0.038 & $(0.111)$ & $(0.124)$ \\
& $(0.086)$ & 0.001 & $-0.300^{\star \star \star}$ \\
Father died & -0.127 & $(0.118)$ & $(0.092)$ \\
Mother died & $(0.080)$ & 0.106 & -0.081 \\
& 0.041 & $(0.069)$ & $(0.094)$ \\
& $(0.056)$ & 0.025 & -0.088 \\
Observations & -0.005 & $(0.098)$ & $(0.112)$ \\
R-squared & $(0.073)$ & 320 & 363 \\
& 683 & 0.173 & 0.117 \\
\hline
\end{tabular}

Notes: Results reported are marginal effects estimated using a Probit. Robust standard errors in brackets. * significant at $10 \%$; *

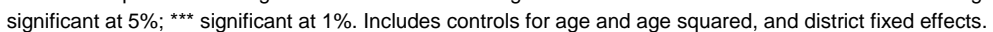




\section{Annex Table 2: The effect of orphanhood, all children at baseline, regardless of} orphan status at baseline (Dependent variable: ever married)

\begin{tabular}{|c|c|c|c|}
\hline & $\begin{array}{l}\text { (1) } \\
\text { All }\end{array}$ & $\begin{array}{c}(2) \\
\text { Women } \\
(17-23 \text { in 2004) }\end{array}$ & $\begin{array}{c}\text { (3) } \\
\text { Men } \\
(20-28 \text { in 2004) }\end{array}$ \\
\hline \multirow[t]{2}{*}{ Male prime-age adult died } & 0.016 & -0.070 & 0.120 \\
\hline & $(0.070)$ & $(0.098)$ & $(0.096)$ \\
\hline \multirow[t]{2}{*}{ Female prime-age adult died } & -0.070 & -0.029 & -0.128 \\
\hline & $(0.062)$ & $(0.088)$ & $(0.088)$ \\
\hline \multirow[t]{2}{*}{ Father died } & $0.072^{\star}$ & 0.083 & 0.066 \\
\hline & $(0.040)$ & $(0.058)$ & $(0.057)$ \\
\hline \multirow[t]{2}{*}{ Mother died } & 0.043 & 0.024 & 0.057 \\
\hline & $(0.045)$ & $(0.068)$ & $(0.063)$ \\
\hline \multicolumn{4}{|l|}{ Baseline characteristics } \\
\hline \multirow[t]{2}{*}{ Head has at least primary schooling } & $-0.089 * \star$ & $-0.163^{\star *}$ & -0.044 \\
\hline & $(0.043)$ & $(0.065)$ & $(0.058)$ \\
\hline \multirow[t]{2}{*}{ Head male } & 0.029 & 0.105 & -0.031 \\
\hline & $(0.050)$ & $(0.076)$ & $(0.067)$ \\
\hline \multirow[t]{2}{*}{ Age of household head } & -0.001 & -0.002 & -0.001 \\
\hline & $(0.001)$ & $(0.002)$ & $(0.002)$ \\
\hline \multirow[t]{2}{*}{ Log of expenditure per capita } & -0.007 & -0.034 & 0.004 \\
\hline & $(0.036)$ & $(0.055)$ & $(0.048)$ \\
\hline \multirow[t]{2}{*}{ Permanent flooring in dwelling } & $-0.138^{\star \star \star}$ & $-0.176^{\star *}$ & $-0.111^{*}$ \\
\hline & $(0.050)$ & $(0.079)$ & $(0.065)$ \\
\hline \multirow[t]{2}{*}{ Non-farm household } & -0.044 & 0.048 & -0.088 \\
\hline & $(0.044)$ & $(0.069)$ & $(0.055)$ \\
\hline \multirow[t]{2}{*}{ Father lives in household } & 0.043 & 0.002 & 0.080 \\
\hline & $(0.048)$ & $(0.075)$ & $(0.064)$ \\
\hline \multirow[t]{2}{*}{ Mother lives in household } & -0.057 & -0.060 & -0.064 \\
\hline & $(0.044)$ & $(0.067)$ & $(0.060)$ \\
\hline Observations & 1,064 & 473 & 591 \\
\hline R-squared & 0.176 & 0.190 & 0.182 \\
\hline
\end{tabular}

Notes: Results reported are marginal effects estimated using a Probit. Robust standard errors in brackets. * significant at $10 \%$; **

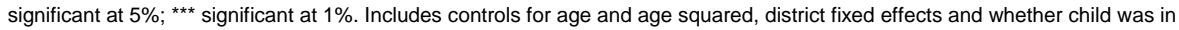
school at baseline. Sample includes children who were already orphaned at baseline. 
Annex Table 3: The effect of orphanhood on probability of marriage by 2004: weighted by inverse of predicted probability of remaining in the sample in 2004 (Dependent variable: ever married)

\begin{tabular}{lccc}
\hline & $\begin{array}{l}(1) \\
\text { All }\end{array}$ & $\begin{array}{c}(2) \\
\text { Women } \\
(17-23 \text { in 2004) }\end{array}$ & $\begin{array}{c}(3) \\
\text { Men } \\
(20-28 \text { in 2004) }\end{array}$ \\
\hline Male prime-age adult died & -0.059 & -0.119 & 0.046 \\
Female prime-age adult died & $(0.091)$ & $(0.135)$ & $(0.120)$ \\
Father died & $-0.133^{\wedge}$ & -0.083 & $-0.291^{\star}$ \\
Mother died & $(0.085)$ & $(0.120)$ & $(0.103)$ \\
& 0.049 & $0.112^{\wedge}$ & -0.027 \\
Number of observations & $(0.066)$ & $(0.077)$ & $(0.117)$ \\
Adjusted R2 & 0.043 & 0.072 & -0.051 \\
\hline
\end{tabular}

Notes: Results reported are marginal effects estimated using a Probit. Robust standard errors in brackets. ^ significant at 15\%; * significant at $10 \%$. Includes controls for age and age squared, district fixed effects and whether child was in school at baseline. Weighted by inverse of predicted probability of remaining in the sample in 2004. 
Beegle \& Krutikova: Adult Mortality and Children's Transition into Marriage 